\title{
Carotid cross-sectional wall area is significantly associated with serum leptin levels, independent of body mass index: the SABPA study
}

\author{
Chiné Pieterse, Alta E Schutte, Carina Mels, Wayne Smith and Rudolph Schutte
}

Hypertension and obesity are serious health burdens in sub-Saharan Africa. Urbanized Africans seem to be more susceptible to the development of these diseases than Caucasians. Current research suggests that leptin may be an important contributor to the development of hypertension and atherosclerosis. The aim of this study was to investigate leptin levels and their associations with cardiovascular function in urbanized Africans and Caucasians. Serum leptin, ambulatory blood pressure and carotid intima-media thickness were measured, and the cross-sectional wall area (CSWA) was calculated. The results showed that Africans had higher leptin levels $(P<0.001)$, ambulatory blood pressure $(P<0.001)$, carotid intima-media thickness $(P<0.01)$ and CSWA $(P<0.01)$ than Caucasians. As we found no interaction between ethnicity and gender for the association between leptin and the cardiovascular variables, we focused mainly on the total group of Africans and Caucasians. In single, partial and multiple regression analyses, positive associations of ambulatory systolic blood pressure $(\beta=0.256 ; P<0.001)$, diastolic blood pressure $(\beta=0.143 ; P=0.012)$, pulse pressure $(\beta=0.327 ; P<0.001)$ and $\operatorname{CSWA}(\beta=0.107 ; P=0.038)$ with leptin were observed. Even after adjusting for body mass index (BMI), the association between CSWA $(\beta=0.107 ; P=0.038)$ and leptin remained. Our findings therefore suggest that leptin may contribute to the development of atherosclerosis, independent of BMI.

Hypertension Research (2012) 35, 1185-1192; doi:10.1038/hr.2012.130; published online 30 August 2012

Keywords: atherosclerosis; blood pressure; cross-sectional wall area; ethnicity; leptin

\section{INTRODUCTION}

Hypertension is a serious public health concern worldwide, and its prevalence in sub-Saharan Africa is rapidly increasing. ${ }^{1}$ The recent prevalence rates in sub-Saharan Africa is proposed to be $16.2 \%$ and is higher in urban than rural populations. ${ }^{2}$ Urbanization may therefore explain the observed variance in hypertension rates in sub-Saharan Africa. ${ }^{3}$ With urbanization, there is a subsequent increase in hypertension and obesity rates-both of which are contributors to a higher cardiovascular disease risk. ${ }^{4}$ The adipocytokine, leptin, is believed to be a possible link between obesity and cardiovascular disease. $^{5}$

Subcutaneous adipose tissue is the primary source of leptin, and its serum levels correlate directly with body fat mass. ${ }^{6}$ Leptin has both beneficial and detrimental effects on the cardiovascular system. On the one hand, it induces vasodilation by promoting nitric oxide release in the endothelium, ${ }^{7}$ but on the other hand, leptin increases sympathetic nerve activity ${ }^{6}$ and promotes the release of vasoconstrictive substances, ${ }^{8}$ which could contribute to obesity-related hypertension. Furthermore, leptin also increases the production of damaging reactive oxygen species (ROS) $)^{9}$ and the secretion of inflammatory markers, ${ }^{10,11}$ which contribute to atherosclerosis. Selective leptin resistance observed in obese animal models and patients with hyperleptinemia include resistance to leptin's metabolic actions; however, the stimulatory effect on the sympathetic nervous system remained intact. ${ }^{12,13} \mathrm{~A}$ hyperleptinemic state also causes endothelial dysfunction and the proliferation of vascular smooth muscle cells, which thereby promotes atherosclerosis. ${ }^{14}$ In addition, it is known that leptin promotes platelet aggregation and arterial thrombosis. ${ }^{15}$ Therefore, leptin possesses atherogenic and growth-promoting properties, which may contribute to an increased risk for cardiovascular disease. ${ }^{16}$ Therefore, as expected, leptin is an independent predictor of cardiovascular events, as observed in Caucasian population groups. ${ }^{17}$

To the best of the authors' knowledge, no studies regarding the associations of 24-h blood pressure and carotid intima-media thickness with leptin have been undertaken in Africans. The aim of this study was therefore to compare leptin levels and their associations with cardiovascular function in urbanized African and Caucasian school teachers. 


\section{METHODS}

\section{Study population}

This study forms part of the Sympathetic activity and Ambulatory Blood Pressure in Africans (SABPA) study, which included 409 African and Caucasian school teachers working in the Potchefstroom district in the North West Province of South Africa. The reason for this target population selection was to obtain a homogenous sample from a similar socioeconomic class. Participants between the ages of 25 and 60 years were included in this study. The exclusion criteria were an oral temperature above $37^{\circ} \mathrm{C}$, usage of $\alpha$ - and $\beta$-blockers, psychotropic substance dependence or abuse, regular blood donations and vaccination in the past three months. Of the 409 subjects, we excluded 1 African and 1 Caucasian male from all analyses owing to missing data. Participants received detailed information about the procedures and objectives of the study before their recruitment. Participants requesting conveyance of information in their home language were assisted. All participants signed an informed consent form. The study complied with all applicable requirements and international regulations, including the Helsinki declaration of 1975 (as revised in 2008) for investigation of human participants. The study was approved by the Ethics Review Board of the North-West University (Potchefstroom Campus).

\section{Cardiovascular measurements}

Ambulatory blood pressure measurements (ABPMs) were conducted during the work week. At $\sim 0800$ hours, an ABPM apparatus (Meditech CE120 Cardiotens; Meditech, Budapest, Hungary) and a two-lead electrocardiogram apparatus were attached to the participant's nondominant arm at their workplace. The ABPM apparatus was programmed to measure blood pressure at 30-min intervals during the day (0800-2200 hours) and every hour during the nighttime. Participants received ambulatory diary cards and were requested to indicate abnormalities such as nausea, headache or stress experienced during their normal daily activities. At 1630 hours, participants were transported to the North-West University and admitted to the Metabolic Unit Research Facility. This facility consists of 10 bedrooms, 2 bathrooms, a living room and a kitchen. Participants received a standardized dinner and at 2030 hours received their last beverage (coffee/tea and two biscuits). They were then allowed to relax by reading, watching television or social interaction and were encouraged to go to bed at 2200 hours. Participants were requested to refrain from alcohol consumption, caffeine and exercise. At 0600 hours, the ABPM apparatus was removed and subsequent measurements commenced. Electrocardiogram and 24-h blood pressure data were downloaded onto a database using the CardioVisions 1.9.0 Personal Edition (Meditech). If $<75 \%$ of the ABPM recordings for a particular participant were successful, the measurements were repeated the next day. The validated ${ }^{18-21}$ Finometer device (FMS, Finapres Measurement Systems, Amsterdam, The Netherlands) was connected, and a 5-min continuous measurement of resting cardiovascular parameters was carried out. During the recording, after $2 \mathrm{~min}$, a return-to-flow systolic calibration was performed to provide an individual subject-level adjustment of the finger arterial pressure with the brachial artery pressure. ${ }^{19}$ Therefore, highest precision in cardiovascular measurements is obtainable only after this calibration, ${ }^{19}$ and blood pressure levels meet the requirements of the Association for the Advancement of Medical Instrumentation. ${ }^{22}$ The Finometer computed the stroke volume, cardiac output and total peripheral resistance online and stored the data in result files. ${ }^{23}$ Total peripheral resistance as part of the nonlinear three-element model (aortic characteristic impedance, arterial compliance and systemic vascular resistance) is computed from a published, ${ }^{24}$ age-dependent, aortic pressure-area relationship and represents the cumulative compliance of the entire arterial systerm. ${ }^{23}$ Carotid intimamedia thickness measurements were obtained using a SonoSite Micromaxx ultrasound system (SonoSite, Bothell, WA, USA) and a 6-13-MHz linear array transducer. Images from at least two optimal angles of the left and right common carotid artery were obtained. Following previously prescribed protocols ${ }^{25}$ these segments were imaged and measured by the same observer. The images were digitized and imported into the Artery Measurement Systems automated software ${ }^{26,27}$ for dedicated analysis of intima-media thickness. A maximal 10-mm segment with good image quality was chosen for analysis. The program automatically identifies the borders of the intima-media of the near and far wall and the inner diameter of the vessel, and calculates the intima-media thickness and diameter from $\sim 100$ discrete measurements throughout the $10-\mathrm{mm}$ segment. This automated analysis was capable of being manually corrected if found to be inappropriate based on visual inspection. Far wall measurements were used for this study. Intraobserver variability for the far wall was $0.04 \mathrm{~mm}$ between two measurements made 4 weeks apart on 10 subjects. We also calculated the cross-sectional wall area (CSWA) to confirm structural and not functional changes in luminal diameter as follows: $\mathrm{CSWA}=\pi(d / 2+\mathrm{CIMT})^{2}-\pi(d / 2)^{2}$, where $\mathrm{d}$ denotes luminal diameter. ${ }^{28,29}$

\section{Anthropometric measurements}

Height (stature) and weight of participants were measured while in their underwear using calibrated instruments (Precision Health Scale, A \& D Company, Tokyo, Japan; Invicta Stadiometer, IP 1465; Invicta, London, UK). Subsequently, the body mass index (BMI) was calculated for each participant. All measurements were obtained in triplicate using standard methods. ${ }^{30}$

\section{Biochemical measurements}

After the cardiovascular and anthropometric measurements were performed, a registered nurse obtained a fasting blood sample with a sterile winged infusion set from the antebrachial vein branches. EDTA, whole blood and serum were stored at $-80^{\circ} \mathrm{C}$. Serum glucose was determined using a timed-end-point method (Unicel DXC 800, Beckman Coulter, Krefeld, Germany). Fasting serum samples for total cholesterol and high-sensitivity C-reactive protein were analyzed using the sequential multiple analyzer computer (Konelab 20i; Thermo Scientific, Vantaa, Finland). Serum ROS were determined using an improved assay system based on the principle of the derivatives of reactive oxygen metabolites test, which is recognized as an efficient method for evaluating oxidative stress in the body. The Bio-Tek FL600 Microplate Fluorescence Reader (Bio-Tek, Instruments, Highland Park, Winooski, VT, USA) was used to measure ROS levels, where $1.0 \mathrm{mgl}^{-1} \mathrm{H}_{2} \mathrm{O}_{2}$ represents one unit of ROS. ${ }^{31}$ For alcohol intake, gamma-glutamyl transferase levels were measured with the UniCel DxC 800 analyzer (Beckman Coulter) on an enzyme rate method. ${ }^{32}$ Serum leptin levels were determined using an enzyme-linked immunosorbent assay kit (Quantikine, R\&D Systems, MN, USA). HIV testing was performed with the First Response HIV Card Test 1-2.0 (PMC Medical, India Pvt, Nani Daman, India) and confirmed with Pareekshak HIV Triline (Bhat Bio-tech India (P) Ltd., Bangalore, India).

\section{Statistical analyses}

For database management and statistical analysis, we used the Statistica software version 10.0 (2010; Statsoft, Tulsa, OK, USA). The distribution of serum leptin, serum glucose, high-sensitivity C-reactive protein and gammaglutamyl transferase were normalized by logarithmic transformation. The central tendency and spread of these variables were represented by the geometric mean and the 5th and 95th percentile intervals. Independent $t$-tests were performed to compare means between groups and the $\chi^{2}$ test was used to compare proportions. Mean values of leptin were plotted by quintiles of the cardiovascular variables to ensure that linear correlation techniques were appropriate. Pearson's correlations were determined, as well as partial correlations after adjustment for ethnicity, gender and age. We also tested interactions of ethnicity or gender for the association between leptin and cardiovascular variables by introducing appropriate interaction terms. Forward stepwise multiple regression analyses were performed in the total group to investigate independent associations of 24-h systolic blood pressure, 24-h diastolic blood pressure, 24-h pulse pressure, intima-media thickness and CSWA with leptin while adjusting for significant covariates (ethnicity, gender, age, total cholesterol, serum glucose, C-reactive protein, ROS, gamma-glutamyl transferase, smoking, physical activity, HIV infection and antihypertensive medication). Intima-media thickness and CSWA were additionally adjusted for 24-h mean arterial pressure and 24-h pulse pressure.

\section{RESULTS}

\section{Characteristics of participants}

Table 1 lists the characteristics of the total group $(n=407)$, as well as the Africans $(n=199)$ and Caucasians $(n=208)$ separately. Africans 
Table 1 Characteristics of study population

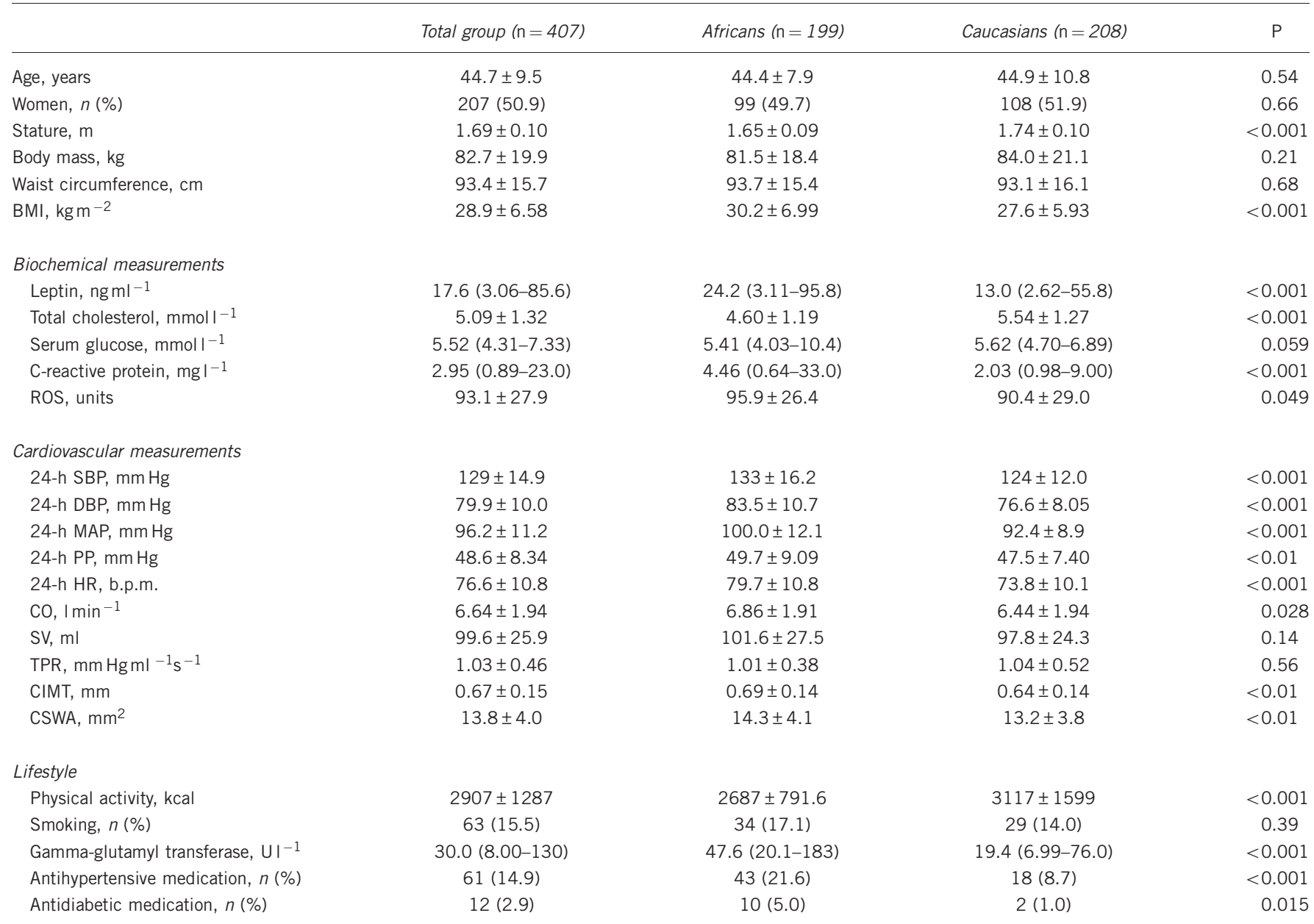

Abbreviations: BMI, body mass index; CIMT, carotid intima-media thickness; CO, cardiac output; CSWA, cross-sectional wall area; DBP, diastolic blood pressure; HR, heart rate; MAP, mean arterial pressure; PP, pulse pressure; ROS, reactive oxygen species: SBP, systolic blood pressure; SV, stroke volume; TPR, total peripheral resistance.

Values are arithmetic mean \pm s.d., geometric mean (5th-95th percentile interval) or number of participants (\%).

$P$ denotes difference between Africans and Caucasians.

were shorter than Caucasians, but body mass and waist circumference did not differ. Both the BMI $(P<0.001)$ and leptin levels $(P<0.001)$ of Africans were higher than Caucasians. In addition, Africans accounted for $36 \%$ of the overweight or obese individuals in the total group, whereas $32 \%$ were Caucasians $(P=0.026)$. Furthermore, Africans had lower total cholesterol $(P<0.001)$, and higher C-reactive protein $(P<0.001)$, ROS $(P=0.049)$, blood pressure $(P<0.001)$, intima-media thickness $(P<0.01)$ and CSWA $(P<0.01)$ than Caucasians. In both Africans and Caucasians, women had significantly higher leptin levels than men $(P<0.001)$.

\section{Unadjusted analyses}

There were no significant interactions with ethnicity or gender for the associations between the cardiovascular variables and leptin. Therefore, our main focus is on the total group. However, for transparency, associations for the separate ethnic and gender groups are also shown. In single regression analyses (Table 2), all cardiovascular variables and ROS showed significant positive associations with leptin in the total group, except for age, 24-h diastolic pressure, intima-media thickness and CSWA. In addition, when the separate ethnic and gender groups were investigated, we found mixed results confirming the lack of interaction obtained with gender and ethnicity. However, the association in African men was prominent where positive associations of all cardiovascular variables including intima-media thickness and CSWA with leptin were found.

\section{Adjusted analyses}

After adjusting for ethnicity, gender and age in the total group (Table 3), we noticed positive associations of all cardiovascular variables and ROS $(P<0.01)$ with leptin. After adjusting for age in the separate ethnic and gender groups, all of the previous unadjusted associations remained. However, the positive correlations of intimamedia thickness and CSWA with leptin in African men disappeared, but positive associations were obtained between CSWA and leptin in Caucasian men and both intima-media thickness and CSWA with leptin in Caucasian women.

With regard to measures of arterial structure and function, the associations obtained in the total group (Table 3) were confirmed in exploratory analyses (Figure 1) where 24-h systolic pressure, 24-h pulse pressure and CSWA were plotted by quintiles of leptin, with adjustment applied for ethnicity, gender and age. The significant positive associations of 24 -h systolic pressure $(P$ for trend $<0.001$ ), 24 -h pulse pressure $(P$ for trend $<0.001)$ and CSWA $(P$ for trend, $0.007)$ with leptin were again evident in the total group. 
Table 2 Unadjusted associations of leptin with age, BMI, cardiovascular variables and ROS

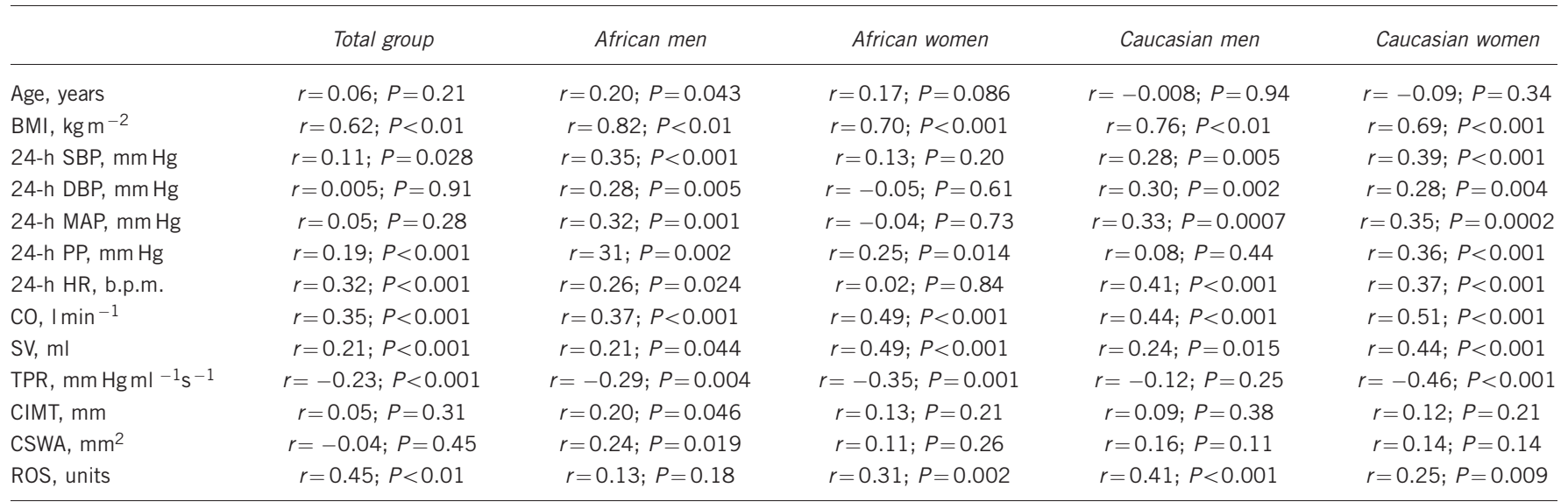

Abbreviations: BMI, body mass index; CIMT, carotid intima-media thickness; CO, cardiac output; CSWA, cross-sectional wall area; DBP, diastolic blood pressure; HR, heart rate; MAP, mean arterial pressure; PP, pulse pressure; ROS, reactive oxygen species; SBP, systolic blood pressure; SV, stroke volume; TPR, total peripheral resistance.

Table 3 Partial correlation coefficients of leptin with BMI, cardiovascular variables and ROS, adjusted for age

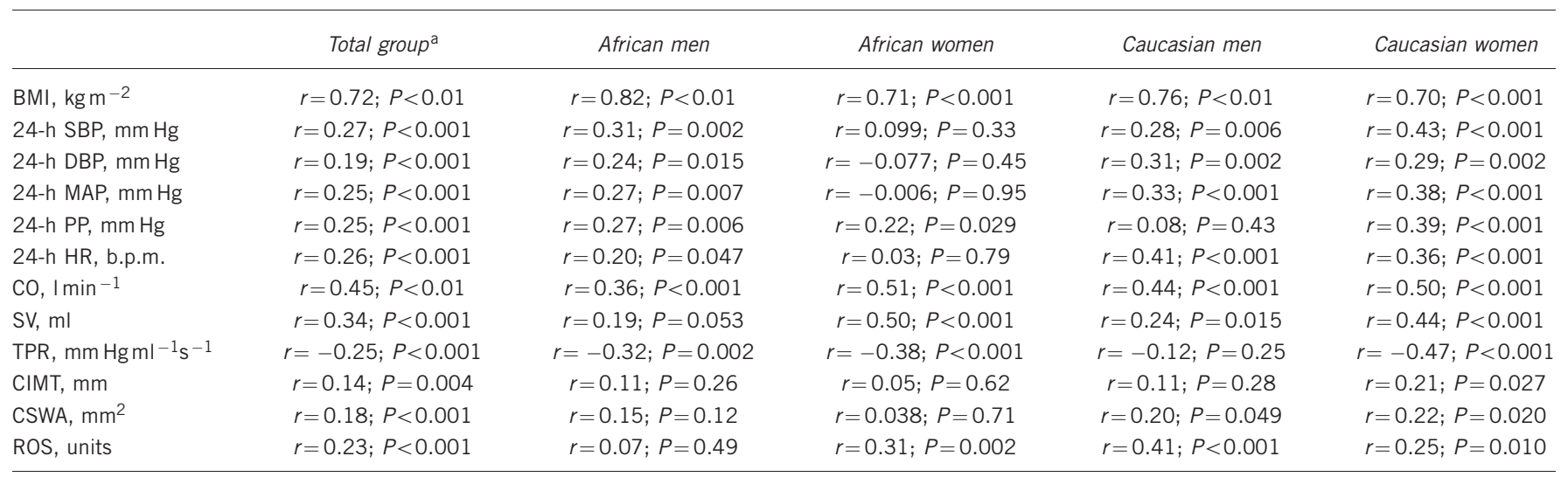

Abbreviations: BMI, body mass index; CIMT, carotid intima-media thickness; CO, cardiac output; CSWA, cross-sectional wall area; DBP, diastolic blood pressure; HR, heart rate; MAP, mean arterial pressure; PP, pulse pressure; ROS, reactive oxygen species; SBP, systolic blood pressure; SV, stroke volume; TPR, total peripheral resistance.

${ }^{a}$ Additionally adjusted for ethnicity and gender.
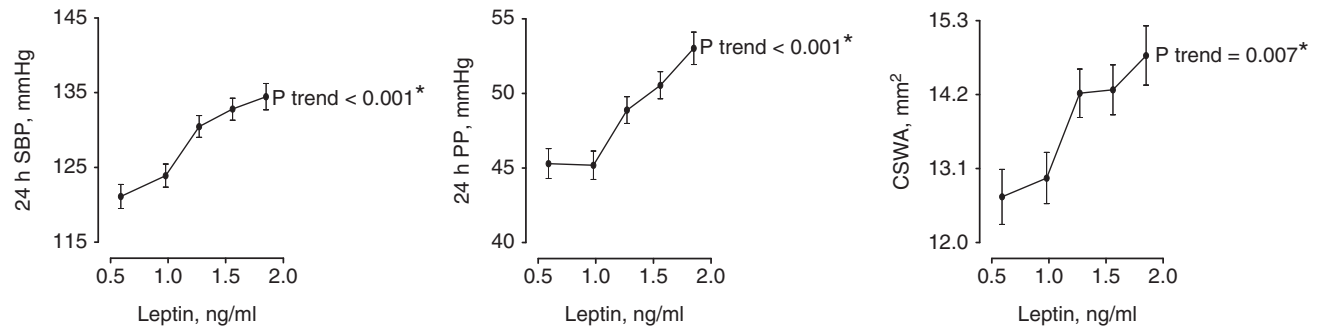

Figure 1 The 24-h SBP, 24-h PP and CSWA by quintiles of leptin levels in the total group adjusted for ethnicity, gender and age. Values are arithmetic mean \pm s.e. $P$ denotes significance for trend; ${ }^{*} P<0.05$ (quintile 1 vs. quintile ${ }_{5}$ ). SBP, systolic blood pressure; PP, pulse pressure.

The independent associations between the cardiovascular variables and leptin are shown in Table 4. With adjustments applied for significant covariates, the previously mentioned associations in the total group were confirmed. Positive associations of all cardiovascular variables with leptin were found except with intima-media thickness $(P=0.23)$. When additionally adjusting for BMI, the positive association of CSWA with leptin remained in the total group $(P=0.038)$, but associations with 24 -h systolic pressure, 24-h diastolic pressure and 24 -h pulse pressure disappeared.

\section{Sensitivity analysis}

The disappearance of the association between 24-h blood pressure and leptin could possibly be due to the volume loading effect associated with increasing BMI. To confirm this in single regression analyses, both leptin $(r=0.21 ; P<0.001)$ and BMI $(r=0.51 ; P<0.01)$ correlated with stroke volume, while 24 -h systolic pressure $(r=0.22$; $P<0.001)$ and 24 -h diastolic pressure $(r=0.07 ; \quad P=0.17)$ also correlated with stroke volume. The association between 24 -h blood pressure and leptin also disappeared after adjusting for stroke volume. 


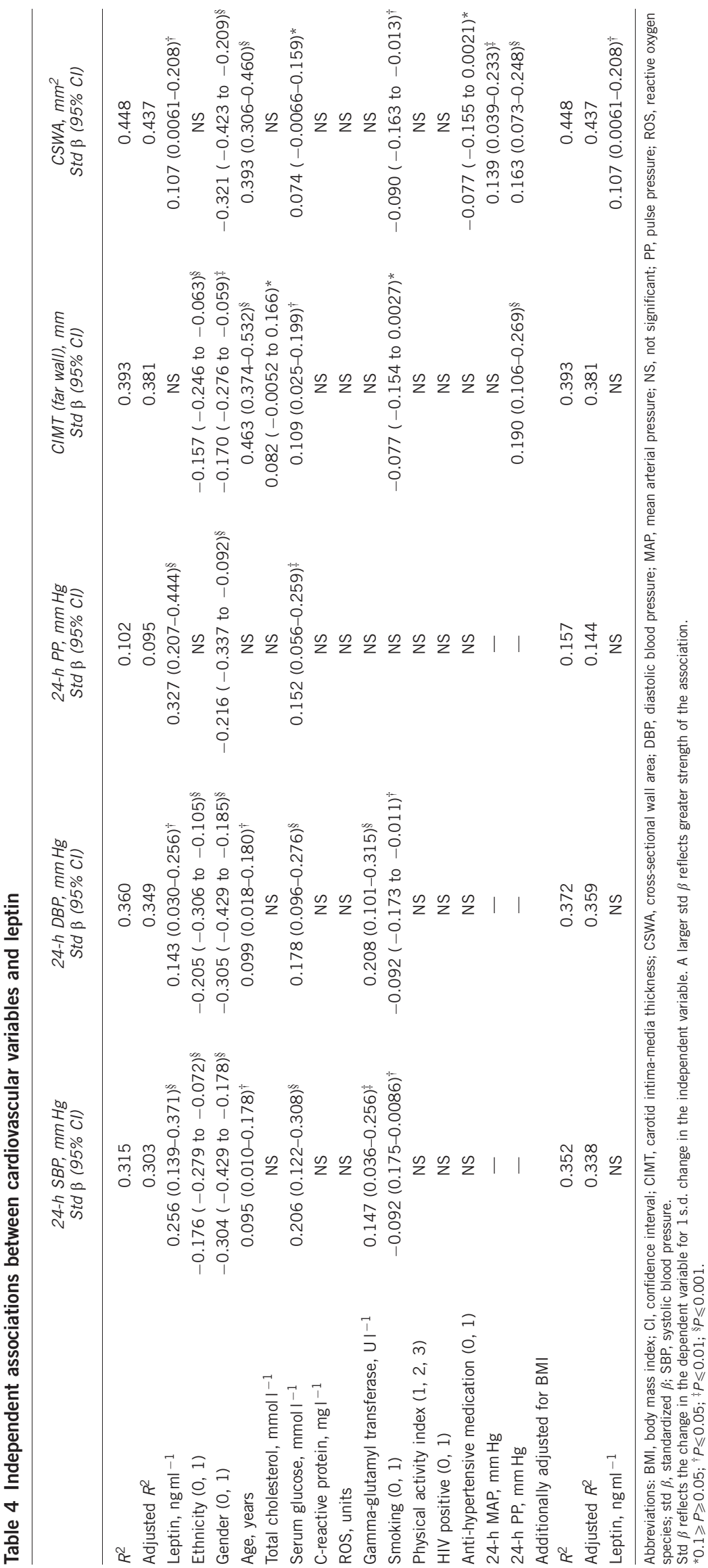


As body fat composition was not measured and BMI is a rough estimate thereof, we also added body surface area and waist-to-hip ratio to the multiple regression model to further investigate the relationship between CSWA and leptin. By doing so, none of the anthropometric measures remained in the model and the result therefore remained unchanged $\left(R^{2}=0.448, \beta=0.107(0.0061-0.208)\right.$, $P=0.038)$. Last, even though the use of antihypertensive medication was included as a binomial variable in the model, we repeated the analysis after excluding 61 treated subjects (BMI still in the model). After this, our results also remained largely unchanged $\left(R^{2}=0.440\right.$, $\beta=0.125(0.016-0.238), P=0.026)$.

\section{DISCUSSION}

The main finding of our study is that a positive association existed between the wall of the carotid artery and the adipocytokine, leptin. This was independent of BMI and other significant covariates. Higher leptin levels may therefore be an important contributor to the development of atherosclerosis in this group, of which $68 \%$ were either overweight or obese.

Previous studies investigating the associations between carotid intima-media thickness and leptin showed contradictory results. A correlation between carotid intima-media thickness and leptin was demonstrated in obese individuals, ${ }^{33}$ whereas other studies involving elderly overweight Caucasian men $^{34}$ and obese children showed no association. In this study, the association of CSWA with leptin remained significant even after adjusting for BMI as well as body surface area and waist-to-hip ratio in sensitivity analysis. ${ }^{35,36}$ This suggests that the increase in CSWA was not due to functional changes to normalize tensile stress, which occur with volume loading due to an increase in fat mass, ${ }^{37}$ but rather that elevated leptin levels contribute to thickening of the arterial wall via mechanisms that are independent of obesity per se. The association between CSWA and leptin may be explained by multiple mechanisms. In vitro studies show that leptin promotes the production of ROS either by reducing antioxidant enzymes or by increasing fatty acid oxidation. ${ }^{38,39}$ In support of these findings, we obtained a strong association between ROS and leptin in this study. Oxidative stress has an important role during the onset of atherosclerosis. ${ }^{40} \mathrm{~A}$ further atherosclerotic contribution of leptin is to induce smooth muscle cell hypertrophy and proliferation via endothelin-1- and angiotensin II-dependent mechanisms. ${ }^{41}$ Angiotensin II also increases the production of ROS ${ }^{42}$ and induces the release of the vasoconstrictor, endothelin- $1 .{ }^{43}$ Leptin also stimulates the secretion of inflammatory markers such as C-reactive protein ${ }^{10}$ and interleukin- $6^{11}$ that are directly involved in the development of endothelial dysfunction and atherosclerosis. However, our finding was independent of ROS and C-reactive protein. Although it is unclear which of these mechanisms involving leptin contribute, or contribute the most, to the development of atherosclerosis in our study group, our robust relationship obtained with CSWA suggests that leptin at least has an important part. Although our findings were independent of BMI and other conventional risk factors, the fact that $68 \%$ of the group was either overweight or obese cannot be ignored. Therefore, although leptin seems to contribute directly to atherosclerosis independent of obesity, it remains the excess adipose tissue that is responsible for the elevated leptin levels and therefore one would expect these effects to be more prominent in overweight and obese individuals.

We also established a positive relationship between ambulatory blood pressure and leptin. This result contributes to controversial findings where associations between blood pressure and leptin were found independent of BMI in some studies, ${ }^{4,45}$ whereas others did not report this. ${ }^{46}$ However, in this study, when BMI was added into our regression model, the associations of 24-h blood pressure and 24-h pulse pressure with leptin disappeared. Possible explanations may be the confounding volume loading effect associated with increasing adiposity, which also raises blood pressure. ${ }^{47,48}$ This is supported by the correlations of stroke volume with leptin, BMI and 24-h systolic pressure, possibly explaining the link between blood pressure and leptin.

The fact that no significant interactions existed with ethnicity or gender for the associations between the cardiovascular variables and leptin could be because our study population consisted of school teachers with a similar socioeconomic status. The relationship between blood pressure, obesity and socioeconomic status is well known $^{49}$ and therefore a similar socioeconomic status seems to yield similar results, irrespective of ethnicity. In addition, we also investigated ethnic and gender differences in leptin levels. Women had higher leptin levels than men, confirming previous findings. ${ }^{50,51}$ On the other hand, previous contradictory results have been found regarding ethnic differences in leptin levels. ${ }^{52,53}$ Our results show that Africans have higher leptin levels than Caucasians, but it is noteworthy that the African group also recorded a higher BMI than their Caucasian counterparts.

The clinical relevance of our findings is that it supports the notion that if the emerging epidemic of obesity in South Africa is left unopposed, the already increasing trends in cardiovascular disease will reach immense proportions. Therefore, future research and clinical studies are needed to fully understand the effects of leptin on the cardiovascular system, and more specifically on the development of hypertension and atherosclerosis. Despite all this uncertainty, leptin treatment to promote weight loss is becoming more popular.

This study has to be interpreted within the context of its limitations and strengths. It could be questioned whether these groups are comparable due to known ethnic differences in fat distribution. ${ }^{50}$ Dietary analyses were not performed before the study to ensure consistent diets. Subcutaneous fat releases more leptin than visceral fat deposits and it is recognized that Africans possess more subcutaneous fat than their Caucasian counterparts for any given BMI. $^{54}$ Moreover, we only estimated body fat composition and distribution by means of BMI, body surface area and waist-to-hip ratio instead of more accurate methods such as dual energy X-ray absorptiometry. The relationship between CSWA and leptin may therefore not be completely independent of body fat. However, adjusting for BMI had a prominent effect regarding the relationship between 24-h blood pressure and leptin. The possibility also exists that dilation of the artery may not accompany any change in carotid intima-media thickness and could directly increase the value of CSWA without any progression of atherosclerosis. ${ }^{28}$ In addition, cross sectional wall area is not an established marker of cardiovascular outcome. However, a recent study found associations between CSWA and outcome (in normotensives and nondiabetics) in a 7-year followup study with over 2000 participants. ${ }^{29}$ In this study, established cardiovascular risk factors such as age, serum glucose, smoking and blood pressure were associated with this marker (Table 4).

In addition, our results were statistically significant, but leptin may contribute to vascular disease risk by interacting with other risk factors. Indeed, the multiplicity of leptin's involvement in vascular physiology, ranging from vasodilation through upregulation of nitric oxide biosynthesis ${ }^{7}$ to promoting atherosclerosis through multiple mechanisms in a leptin-resistant state, ${ }^{6,41}$ makes it difficult to isolate the direct effects of leptin. This was a selected target population; 
therefore, results cannot be extrapolated to other population groups. Although our results were consistent after multiple adjustments, we cannot exclude the possibility that our associations were due to residual confounding. This was a cross-sectional study and therefore we cannot infer causality. Apart from this, we conducted a welldesigned study under highly controlled conditions. To conclude, circulating leptin levels was associated with carotid CSWA, a marker of atherosclerotic progression, independent of BMI. The potential implication of this finding is that leptin seems to contribute to the development of atherosclerosis and that care should be taken when administering leptin in the treatment of obesity.

\section{CONFLICT OF INTEREST}

The authors declare no conflict of interest.

\section{ACKNOWLEDGEMENTS}

The Sympathetic activity and Ambulatory Blood Pressure in Africans study would not have been possible without the voluntary collaboration of the participants and the Department of Education, North West province, South Africa. We gratefully acknowledge the technical assistance of Mrs Tina Scholtz, Sr Chrissie Lessing and Dr Szabolcs Péter. Research included in this study was partially funded by the National Research Foundation, South Africa; the North-West University, Potchefstroom, South Africa; and the Metabolic Syndrome Institute, France.

1 Addo J, Smeeth L, Leon DA. Hypertension in sub-saharan Africa: a systematic review. Hypertension 2007; 50: 1012-1018.

2 Poulter NR. Current and projected prevalence of arterial hypertension in sub-Saharan Africa by sex, age and habitat: an estimate from population studies. J Hypertens 2011; 29: 1281-1282.

3 Twagirumukiza M, De BD, Kips JG, de BG, Stichele RV, Van Bortel LM. Current and projected prevalence of arterial hypertension in sub-Saharan Africa by sex, age and habitat: an estimate from population studies. J Hypertens 2011; 29: 1243-1252.

4 Opie LH. Seedat YK. Hypertension in sub-Saharan African populations. Circulation 2005; 112: 3562-3568.

5 Patel SB, Reams GP, Spear RM, Freeman RH, Villarreal D. Leptin: linking obesity, the metabolic syndrome, and cardiovascular disease. Curr Hypertens Rep 2008; 10 : 131-137.

6 Fain JN, Madan AK, Hiler ML, Cheema P, Bahouth SW. Comparison of the release of adipokines by adipose tissue, adipose tissue matrix, and adipocytes from visceral and subcutaneous abdominal adipose tissues of obese humans. Endocrinology 2004; 145: 2273-2282

7 Vecchione C, Maffei A, Colella S, Aretini A, Poulet R, Frati G, Gentile MT, Fratta L, Trimarco V, Trimarco B, Lembo G. Leptin effect on endothelial nitric oxide is mediated through Akt-endothelial nitric oxide synthase phosphorylation pathway. Diabetes 2002; 51: 168-173.

8 Quehenberger P, Exner M, Sunder-Plassmann R, Ruzicka K, Bieglmayer C, Endler G, Muellner C, Speiser W, Wagner O. Leptin induces endothelin-1 in endothelial cells in vitro. Circ Res 2002; 90: 711-718.

9 Bouloumie A, Marumo T, Lafontan M, Busse R. Leptin induces oxidative stress in human endothelial cells. FASEB J 1999; 13: 1231-1238.

10 Koh KK, Quon MJ, Lee SJ, Han SH, Ahn JY, Kim JA, Chung WJ, Lee Y, Shin EK. Efonidipine simultaneously improves blood pressure, endothelial function, and metabolic parameters in nondiabetic patients with hypertension. Diabetes Care 2007; 30: 1605-1607

11 Loffreda S, Yang SQ, Lin HZ, Karp CL, Brengman ML, Wang DJ, Klein AS, Bulkley GB, Bao C, Noble PW, Lane MD, Diehl AM. Leptin regulates proinflammatory immune responses. FASEB J 1998; 12: 57-65.

12 Koh KK, Park SM, Quon MJ. Leptin and cardiovascular disease: response to therapeutic interventions. Circulation 2008; 117: 3238-3249.

13 Correia ML, Haynes WG, Rahmouni K, Morgan DA, Sivitz WI, Mark AL. The concept of selective leptin resistance: evidence from agouti yellow obese mice. Diabetes 2002; 51: 439-442.

14 Beltowski J. Leptin and atherosclerosis. Atherosclerosis 2006; 189: 47-60.

15 Konstantinides S, Schafer K, Koschnick S, Loskutoff DJ. Leptin-dependent platelet aggregation and arterial thrombosis suggests a mechanism for atherothrombotic disease in obesity. J Clin Invest 2001; 108: 1533-1540.

16 Van Gaal LF, Mertens IL, De Block CE. Mechanisms linking obesity with cardiovascular disease. Nature 2006; 444: 875-880.

17 Schulze PC, Kratzsch J. Leptin as a new diagnostic tool in chronic heart failure. Clin Chim Acta 2005; 362: 1-11.
18 Imholz BP, Wieling W, van Montfrans GA, Wesseling KH. Fifteen years experience with finger arterial pressure monitoring: assessment of the technology. Cardiovasc Res 1998; 38: 605-616.

19 Guelen I, Westerhof BE, van der Sar GL, van Montfrans GA, Kiemeneij F, Wesseling KH, Bos WJ. Validation of brachial artery pressure reconstruction from finger arterial pressure. J Hypertens 2008; 26: 1321-1327.

20 Schutte AE, Huisman HW, van Rooyen JM, Malan NT, Schutte R. Validation of the Finometer device for measurement of blood pressure in black women. J Hum Hypertens 2004; 18: 79-84.

21 Schutte AE, Huisman HW, van Rooyen JM, Oosthuizen W, Jerling JC. Sensitivity of the Finometer device in detecting acute and medium-term changes in cardiovascular function. Blood Press Monit 2003; 8: 195-201.

22 AAMI. American National Standard for Electronic or Automated Sphygmomanometers. Association for the Advancement for Medical Instrumentation, Arlington, 2002.

23 Wesseling KH, Jansen JR, Settels JJ, Schreuder JJ. Computation of aortic flow from pressure in humans using a nonlinear, three-element model. J Appl Physiol 1993; 74: 2566-2573.

24 Langewouters GJ, Wesseling KH, Goedhard WJ. The static elastic properties of 45 human thoracic and 20 abdominal aortas in vitro and the parameters of a new model. J Biomech 1984; 17: 425-435.

25 Touboul PJ, Hennerici MG, Meairs S, Adams H, Amarenco P, Bornstein N, Csiba L, Desvarieux M, Ebrahim S, Fatar M, Hernandez HR, Jaff M, Kownator S, Prati P, Rundek T, Sitzer M, Schminke U, Tardif JC, Taylor A, Vicaut E, Woo KS, Zannad F, Zureik M. Mannheim carotid intima-media thickness consensus (2004-2006). An update on behalf of the Advisory Board of the 3rd and 4th Watching the Risk Symposium, 13th and 15th European Stroke Conferences, Mannheim, Germany, 2004, and Brussels, Belgium, 2006. Cerebrovasc Dis 2007; 23: 75-80.

26 Liang Q, Wendelhag I, Wikstrand J, Gustavsson T. A multiscale dynamic programming procedure for boundary detection in ultrasonic artery images. IEEE Trans Med Imaging 2000; 19: 127-142.

27 Wendelhag I, Liang Q, Gustavsson T, Wikstrand J. A new automated computerized analyzing system simplifies readings and reduces the variability in ultrasound measurement of intima-media thickness. Stroke 1997; 28: 2195-2200.

28 Roman MJ, Pickering TG, Schwartz JE, Pini R, Devereux RB. Relation of arterial structure and function to left ventricular geometric patterns in hypertensive adults. J Am Coll Cardiol 1996; 28: 751-756.

29 Roman MJ, Kizer JR, Best LG, Lee ET, Howard BV, Shara NM, Devereux RB. Vascular biomarkers in the prediction of clinical cardiovascular disease: the Strong Heart Study. Hypertension 2012; 59: 29-35

30 Norton K, Olds T. Anthropometrica: A Textbook of Body Measurements for Sport and Health Courses. Sydney, UNSW Press, 1996.

31 Hayashi I, Morishita Y, Imai K, Nakamura M, Nakachi K, Hayashi T. High-throughput spectrophotometric assay of reactive oxygen species in serum. Mutat Res 2007; 631: 55-61.

32 Herzum I, Rieger T, Funke J. Evaluation of the consolidated Beckman Coulter UniCel DxC 880i analyzer_A. Clin Chem Lab Med 2008; 46: A72.

33 Ciccone M, Vettor R, Pannacciulli N, Minenna A, Bellacicco M, Rizzon P, Giorgino R, De PG. Plasma leptin is independently associated with the intima-media thickness of the common carotid artery. Int J Obes Relat Metab Disord 2001; 25: 805-810.

34 van den Beld AW, Bots ML, Janssen JA, Pols HA, Lamberts SW, Grobbee DE. Endogenous hormones and carotid atherosclerosis in elderly men. Am J Epidemiol 2003; 157: 25-31.

35 Mangge H, Schauenstein K, Stroedter L, Griesl A, Maerz W, Borkenstein M. Low grade inflammation in juvenile obesity and type 1 diabetes associated with early signs of atherosclerosis. Exp Clin Endocrinol Diabetes 2004; 112: 378-382.

36 Bodary PF, Gu S, Shen Y, Hasty AH, Buckler JM, Eitzman DT. Recombinant leptin promotes atherosclerosis and thrombosis in apolipoprotein E-deficient mice. Arterioscler Thromb Vasc Biol 2005; 25: e119-e122.

37 Kozakova M, Palombo C, Paterni M, Anderwald CH, Konrad T, Colgan MP, Flyvbjerg A, Dekker J. Body composition and common carotid artery remodeling in a healthy population. J Clin Endocrinol Metab 2008. 93. 3325-3332.

38 Yamagishi SI, Edelstein D, Du XL, Kaneda Y, Guzman M, Brownlee M. Leptin induces mitochondrial superoxide production and monocyte chemoattractant protein-1 expression in aortic endothelial cells by increasing fatty acid oxidation via protein kinase $\mathrm{A}$. J Biol Chem 2001; 276: 25096-25100.

39 Beltowski J, Wojcicka G, Jamroz A. Leptin decreases plasma paraoxonase 1 (PON1) activity and induces oxidative stress: the possible novel mechanism for proatherogenic effect of chronic hyperleptinemia. Atherosclerosis 2003; 170: 21-29.

40 Madamanchi NR, Vendrov A, Runge MS. Oxidative stress and vascular disease. Arterioscler Thromb Vasc Biol 2005; 25: 29-38.

41 Zeidan A, Purdham DM, Rajapurohitam V, Javadov S, Chakrabarti S, Karmazyn M. Leptin induces vascular smooth muscle cell hypertrophy through angiotensin II- and endothelin-1-dependent mechanisms and mediates stretch-induced hypertrophy. J Pharmacol Exp Ther 2005; 315: 1075-1084.

42 Yanagitani Y, Rakugi H, Okamura A, Moriguchi K, Takiuchi S, Ohishi M, Suzuki K, Higaki J, Ogihara T. Angiotensin II type 1 receptor-mediated peroxide production in human macrophages. Hypertension 1999; 33: 335-339.

43 Imai T, Hirata Y, Emori T, Yanagisawa M, Masaki T, Marumo F. Induction of endothelin1 gene by angiotensin and vasopressin in endothelial cells. Hypertension 1992; 19: 753-757.

44 Lindgarde F, Soderberg S, Olsson T, Ercilla MB, Correa LR, Ahren B. Overweight is associated with lower serum leptin in Peruvian Indian than in Caucasian women: a dissociation contributing to low blood pressure? Metabolism 2001; 50: 325-329. 
45 Shankar A, Xiao J. Positive relationship between plasma leptin level and hypertension. Hypertension 2010; 56: 623-628.

46 Takizawa H, Ura N, Saitoh S, Wang L, Higashiura K, Takagi S, Takada M, Togashi N, Nakano M, Hayashi Y, Shimamoto K. Gender difference in the relationships among hyperleptinemia, hyperinsulinemia, and hypertension. Clin Exp Hypertens 2001; 23: 357-368.

47 Blum WF, Englaro P, Hanitsch S, Juul A, Hertel NT, Muller J, Skakkebaek NE, Heiman ML, Birkett M, Attanasio AM, Kiess W, Rascher W. Plasma leptin levels in healthy children and adolescents: dependence on body mass index, body fat mass, gender, pubertal stage, and testosterone. J Clin Endocrinol Metab 1997; 82: 2904-2910.

48 Engeli S, Sharma AM. The renin-angiotensin system and natriuretic peptides in obesity-associated hypertension. J Mol Med 2001; 79: 21-29.

49 Bovet P, Ross AG, Gervasoni JP, Mkamba M, Mtasiwa DM, Lengeler C, Whiting D, Paccaud F. Distribution of blood pressure, body mass index and smoking habits in the urban population of Dar es Salaam, Tanzania, and associations with socioeconomic status. Int J Epidemiol 2002; 31: 240-247.
50 Donahue RP, Zimmet P, Bean JA, Decourten M, Carlo Donahue RA, Collier G, Goldberg RB, Prineas RJ, Skyler J, Schneiderman N. Cigarette smoking, alcohol use, and physical activity in relation to serum leptin levels in a multiethnic population: The Miami Community Health Study. Ann Epidemiol 1999; 9: 108-113.

51 Iputo JE, Robinson D, Mguni M. Serum leptin concentration in a rural African population. East Afr Med J 2001; 78: 484-488.

52 Schutte R, Huisman HW, Schutte AE, Malan NT. Leptin is favourably associated with vascular function in obese Caucasians, but not in obese Africans. J Hum Hypertens 2005; 19: 933-939.

53 Nicklas BJ, Toth MJ, Goldberg AP, Poehlman ET. Racial differences in plasma leptin concentrations in obese postmenopausal women. J Clin Endocrinol Metab 1997; 82: 315-317.

54 Tittelbach TJ, Berman DM, Nicklas BJ, Ryan AS, Goldberg AP. Racial differences in adipocyte size and relationship to the metabolic syndrome in obese women. Obes Res 2004; 12: 990-998. 